\title{
KEANEKARAGAMAN HAMA PADA TANAMAN MELON (Cucumis melo L.)
}

The Diversity of Insects in Melon Plants (Cucumis melo L.)

\author{
Sumeinika Fitria Lizmah ${ }^{1 *}$, Resti Yusniar Gea ${ }^{2}$ \\ ${ }^{1}$ Dosen Prodi Agroteknologi, Fakultas Pertanian, Universitas Teuku Umar, Meulaboh \\ ${ }^{2}$ Mahasiswa Prodi. Agroteknologi, Fakultas Pertanian, Universitas Teuku Umar, Meulaboh \\ *email korespondesi: sumeinikafitrializmah@utu.ac.id
}

\begin{abstract}
The production of melon was decline due to decreased production area and also pest and disease offence. The pest attacks occur in the vegetative and generative phase, but the most damaging and detrimental are in generative phase. This study aims to determine the diversity of insects on melon plants. The study was conducted in September 2018 in experimental gardens and laboratory of Agriculture Faculty, Teuku Umar University. The results of the study obtained the abundance of insects in melon plants amounted to 374 individu, which consists of 38 spesies. Insects are found to have different character, there are as pest, parasitoid, and predator. The fruit flies (Tephritidae) is the dominant of pest that attack melon in generative phase. Diversity of Shannon-Wienner indeks shows 0.820, that mean the diversity in melon plant in generative phase was lowly.
\end{abstract}

Key word: diversity, fruit flies, insects, melon

\section{PENDAHULUAN}

Melon (Cucumis melo L.) merupakan tanaman buah semusim dari famili Cucurbitaceae, yang telah banyak dibudidayakan di Indonesia, baik berskala kecil maupun agribisnis (Anindita 2009). Sebagai komoditas hortikultura yang cukup potensial karena memiliki nilai ekonomi yang cukup tinggi, peningkatan produksi dan kualitas buah melon masih memerlukan penanganan intensif (Daryono et al. 2011).

Produksi melon di Indonesia pada Tahun 2014 berjumlah 150,374 ton (Dirjen Hortikultura), sedangkan pada Tahun 2015 sebesar 137,887 ton dan Tahun 2016 sebesar 117,341 ton (BPS 2016). Melihat data tersebut, produksi melon nasional terus mengalami penurunan dalam tiga tahun terakhir. Pada tahun 2016, hasil tanaman melon mengalami penurunan sebesar 1.53 ton/ha dari 18.64 ton/ha pada tahun 2015 menjadi 17.11 ton/ha pada tahun 2016 (BPS 2016). Penurunan hasil tersebut dipicu oleh penurunan luas panen (7,396 ha menjadi 6,859 ha) dari tahun 2015 ke tahun 2016 (BPS 2016), perubahan iklim, dan juga serangan hama dan penyakit (Rukmana 2006).

Serangan hama pada tanaman melon dapat terjadi pada semua stadia pertumbuhan tanaman melon. Pada fase vegetatif, tanaman melon rentan terhadap serangan bekicot, larva kumbang, jangkrik, dan belalang. Memasuki fase pembungaan, hama yang menyerang melon diantaranya ulat, lalat buah, belalang, dan oteng-oteng (Aulacophora similis). Sementara pada fase pembuahan terjadi serangan hama kepik hitam (Leptoglosus australis), ulat daun, lalat buah, belalang dan dan otengoteng (Aulacophora similis) (Awaludin et al. 2010). 
Menurut Rukmana (2006), beberapa hama penting yang umumnya menyerang tanaman melon yaitu lalat buah (Bactrocera spp.), kumbang daun (Aulocophora similis), ulat daun (Palpita sp.), Aphids (Myzus persicae), Thrips sp., tungau (Tetranychus sp.), ulat grayak (Spodoptera litura), ulat tanah (Agrotis ipsilon), dan cacing tanah (Nematode sp.).

Lalat buah (Famili Tephritidae) merupakan salah satu hama yang berpotensi besar dalam penurunan produksi melon. Di Indonesia pada saat ini telah dilaporkan terdapat 66 spesies lalat buah. Di antara spesies itu, yang dikenal sangat merusak yaitu Bactrocera spp. (Rante 2000). Serangan hama ini menyebabkan kerugian yang cukup besar, baik secara kuantitas maupun kualitas. Luas serangan lalat buah di Indonesia mencapai 4,790 ha dengan kerugian mencapai 21.99 miliar rupiah (Huda 2009).

Pada umumnya kerusakan oleh lalat buah adalah akibat dari kegiatan larva dalam jaringan buah, biasanya diikuti oleh pembusukan yang disebabkan oleh masuknya organisme sekunder. Buah melon yang terinvestasi lalat buah ukurannya kecil tetapi warnanya menjadi kuning sehingga buah melon banyak mengalami pembusukan (Kranz et al. 1997).

Tingkat serangan hama pada tanaman melon di lapangan sangat tinggi. Lalat buah akan memakan bagian dalam atau daging buah melon sampai habis, terkadang bagian luar melon terlihat mulus tetapi bagian dalam atau daging buah sudah membusuk. Hal inilah yang dapat menurunkan produktivitas tanaman hortikultura salah satunya adalah tanaman melon (Antari et al. 2014).

Indeks keanekaragaman dapat digunakan untuk menyatakan hubungan kelimpahan spesies dalam komunitas. Nilai keanekeragaman menggambarkan kondisi lingkungan dalam ekosistem. Semakin rendah nilai keanekaragaman, maka kelimpahan spesies di dalam ekosistem tersebut juga rendah dengan kondisi lingkungan yang rendah atau belum stabil. Sebaliknya pada kondisi lingkungan atau ekosistem yang cenderung stabil, maka indeks keanekaragaman makhluk hidup di dalamnya relatif tinggi (Siregar et al. 2014).

Pengetahuan

mengenai

keanekaragaman jenis hama yang menyerang tanaman melon dapat menjadi langkah awal dalam mengendalikan hamahama tersebut sekaligus menjadi acuan pengukuran suatu ekosistem pertanian. Keberhasilan suatu pengendalian ditentukaan dari ketepatan teknik dan sasaran hama yang akan dikendalian. Oleh sebab itu pengamatan jenis hama yang terdapat pada tanaman melon ini penting untuk dilakukan.

Tujuan dari penelitian ini adalah untuk mengetahui keanekaragaman dan komposisi hama pada tanaman melon.

\section{METODE PENELITIAN}

\section{Tempat dan Waktu}

Penelitian ini dilakukan pada pertanaman melon di Kebun Percobaan dan Laboratorium Fakultas Pertanian Universitas Teuku Umar, Meulaboh Aceh Barat yang dilaksanakan bulan September 2017.

\section{Alat dan Bahan}

Alat yang digunakan antara lain botol koleksi, kuas kecil, kamera, alat tulis, mikroskop stereo, cawan petri dan pinset. Bahan yang digunakan meliputi tanaman melon, Alkohol 70\% dan kertas label.

\section{Pelaksanaan Penelitian}

Pengambilan sampel serangga menggunakan metode purposive sampling, dengan teknik transek atau pengamatan langsung pada bagian tanaman melon yang telah ditentukan. Terdapat 9 bedengan pengamatan dengan jumlah 3 tanaman sampel pada setiap bedengan, sehingga keseluruhan tanaman sampel bertotal 27 tanaman. 
Pengambilan serangga dilakukan pada pagi hari dengan ulangan pengambilan sebanyak tiga kali, interval pengoleksian serangga setiap tiga hari sekali. Setiap serangga yang ditemukan baik pada perakaran, batang, daun, bunga dan buah dimasukkan ke dalam botol koleksi yang berisi alkohol $70 \%$ dan diberikan keterangan label sesuai dengan tanggal dan tanaman sampel. Buah melon yang terlihat sudah terserang hama diambil dan disimpan dalam wadah untuk mengetahui jenis serangga yang menginvestasinya. Selanjutnya seranggaserangga tersebut dibawa ke laboratorium untuk diidentifikasi lebih lanjut.

Data serangga yang diperoleh akan dianalisis berdasarkan indeks keanekaragaman shaonnon-Wiener dengan rumus:

$$
\mathrm{H}^{\prime}=-\sum p i \ln p i
$$

dimana:

H' : Indeks keanekaragaman ShannonWiener

pi $\quad:(\mathrm{ni} / \mathrm{N})$

ni : jumlah individu spesies ke-i

$\mathrm{N} \quad$ : jumlah total individu

Kriteria penilaian indeks Shannon-Wiener adalah sebagai berikut:

$\mathrm{H}<1$ maka keanekaragaman rendah

H 1-3 maka keanekaragaman sedang

$\mathrm{H}>3$ maka keanekaragaman tinggi

\section{HASIL DAN PEMBAHASAN}

Kelimpahan serangga pada tanaman melon berjumlah 374 individu, yang terdiri dari 38 spesies. Serangga yang ditemukan memiliki peran yang berbedabeda yaitu hama, parasitoid, dan predator (Tabel 1).

Tabel 1. Kelimpahan serangga pada tanaman melon fase generatif

\begin{tabular}{|c|c|c|c|c|c|c|}
\hline \multirow{2}{*}{ No } & \multirow{2}{*}{ Spesies } & \multicolumn{3}{|c|}{ Jumlah Individu/Ulangan } & \multirow{2}{*}{ Total } & \multirow{2}{*}{ Peran } \\
\hline & & 1 & 2 & 3 & & \\
\hline 1 & Acanthinevania sp. & 0 & 1 & 0 & 1 & Parasitoid \\
\hline 2 & Agromyzidae sp.01 & 1 & 0 & 0 & 1 & Hama \\
\hline 3 & Agromyzidae sp.02 & 0 & 1 & 0 & 1 & Hama \\
\hline 4 & Agromyzidae sp.03 & 0 & 0 & 1 & 1 & Hama \\
\hline 5 & Agromyzidae sp.04 & 0 & 0 & 1 & 1 & Hama \\
\hline 6 & Aulacophora sp. & 0 & 1 & 2 & 3 & Hama \\
\hline 7 & Batrocera sp. (Lalat buah) & 38 & 158 & 131 & 327 & Hama \\
\hline 8 & Braconidae sp.01 & 3 & 0 & 0 & 3 & Parasitod \\
\hline 9 & Carabidae sp.01 & 0 & 1 & 0 & 1 & Hama \\
\hline 10 & Cerambycdae sp.01 & 2 & 0 & 0 & 2 & Hama \\
\hline 11 & Cerambycidae sp.02 & 1 & 0 & 0 & 1 & Hama \\
\hline 12 & Cerambycidae sp.03 & 1 & 1 & 0 & 2 & Hama \\
\hline 13 & Cerambycidae sp.04 & 0 & 1 & 0 & 1 & Hama \\
\hline 14 & Cerambycidae sp.05 & 0 & 1 & 0 & 1 & Hama \\
\hline 15 & Cerambycidae sp.06 & 0 & 0 & 2 & 2 & Hama \\
\hline 16 & Cerambycidae sp.07 & 0 & 0 & 1 & 1 & Hama \\
\hline 17 & Chysochus auratus & 0 & 1 & 0 & 1 & Hama \\
\hline 18 & Cicadellidae sp. & 0 & 1 & 0 & 1 & Hama \\
\hline 19 & Coccinella sp. & 1 & 0 & 0 & 1 & Hama \\
\hline 20 & Coleoptera sp.01 & 2 & 0 & 0 & 2 & Hama \\
\hline
\end{tabular}




\begin{tabular}{|c|c|c|c|c|c|c|}
\hline 21 & Coleoptera sp.02 & 0 & 1 & 0 & 1 & Hama \\
\hline 22 & Coleoptera sp.03 & 0 & 0 & 1 & 1 & Hama \\
\hline 23 & Coreidae sp.01 & 0 & 1 & 0 & 1 & Hama \\
\hline 24 & Curtonotidae sp. & 0 & 0 & 1 & 1 & Hama \\
\hline 25 & Formicidae sp.01 & 0 & 3 & 0 & 3 & Hama \\
\hline 26 & Ichneumonidae sp.01 & 0 & 1 & 0 & 1 & Parasitoid \\
\hline 27 & Kecoa tanah & 0 & 1 & 0 & 1 & Hama \\
\hline 28 & Kepik & 0 & 0 & 1 & 1 & Hama \\
\hline 29 & Kutu daun (Aphis gossypii) & 1 & 0 & 0 & 1 & Hama \\
\hline 30 & Leptoglossus sp. & 0 & 0 & 1 & 1 & Hama \\
\hline 31 & Oulema sp. & 0 & 0 & 1 & 1 & Hama \\
\hline 32 & Pentatomidae sp.01 & 1 & 0 & 0 & 1 & Hama \\
\hline 33 & Pentatomidae sp.02 & 0 & 1 & 0 & 1 & Hama \\
\hline 34 & Polistes sp. & 0 & 1 & 0 & 1 & Hama \\
\hline 35 & Specidae sp.01 & 1 & 0 & 0 & 1 & Predator \\
\hline 36 & Specidae sp.02 & 0 & 1 & 0 & 1 & Predator \\
\hline 37 & Tetrigidae sp.01 & 1 & 0 & 0 & 1 & Hama \\
\hline 38 & Typhocybinae sp. & 0 & 1 & 0 & 1 & Hama \\
\hline \multicolumn{4}{|r|}{ Total } & & 374 & \\
\hline
\end{tabular}

Hama dominan yang ditemukan pada tanaman melon di fase generatif yaitu lalat buah sebanyak 327 individu. Lalat buah ini ditemukan masih berupa larva yang sudah menyerang buah-buah melon berukuran kecil. Serangan hama ini dicirikan dengan adanya titik hitam pada kulit buah (Gambar 1). Akibatnya buah yang terinvestasi hama ini menjadi berair, membusuk, serta jatuh sebelum matang.

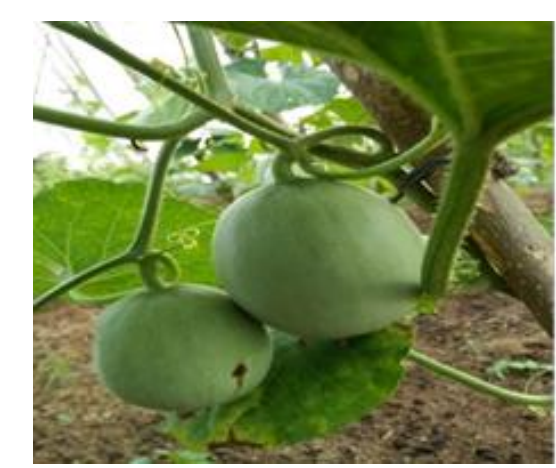

Gambar 1. Buah melon yang terkena lalat buah

Menurut Van Sauers \& Muller (2005), buah yang terserang biasanya terdapat lubang kecil pada kulit buah dan terutama menyerang buah-buah yang hampi masak. lubang kecil pada kulit buah buah merupakan bekas tusukan ovipositor (alat peletak telur) lalat betina saat meletakkan telur ke dalam buah melon. Selanjutnya karena aktivitas larva di dalam buah seperti memakan daging buah, menyebabkan bekas tusukan tersebut meluas dan buah menjadi busuk sebelum masak. Kerugian yang disebabkan oleh hama ini mencapai 30-60\%. Kerusakan yang ditimbulkan oleh larvanya akan menyebabkan gugurnya buah sebelum mencapai kematangan yang diinginkan.

Menurut Kardinan (2003), serangan lalat buah menimbulkan kerugian secara kualitas maupun kuantitas. Kerugian secara kuantitas misalnya kerontokan pada buah-buah muda atau buah yang belum matang. Secara kualitas, adanya lalat buah menyebabkan buah membusuk dan berisi belatung di dalamnya. Buah tersebut apabila dibelah, pada daging buah terdapat ulat-ulat kecil dengan ukuran antara 4-10 $\mathrm{mm}$ yang biasanya meloncat apabila tersentuh. Selain itu, Kardinan (2003) juga menambahkan jika buah yang terinfeksi hama ini juga dapat mnjadi vektor bakteri Escherechia coli yang berbahaya bagi pencernaan manusia. 
Selain lalat buah, hama dominan yang ditemukan pada tanaman melon adalah hama jenis Cerambycidae. Cerambycidae adalah serangga penting dalam ekosistem hutan karena ketergantungan mereka pada sumber makanan di berbagai jenis pohon. Lokasi penanaman melon merupakan lahan yang baru dibuka, dahulunya ditumbuhi pepohonan dan semak belukar, sehingga peluang ditemukannya kumbang ini pada saat pengamatan cukup tinggi. Selain itu adanya sisa-sisa pohon yang ditebang yang merupakan habitat kumbang kayu, juga menambah kemungkinan diperolehnya sejumlah individu cerambycidae. Sebagian besar larva spesies Cerambycidae hidup sebagai pengebor kayu, yang cenderung memilih kayu mati atau kering yang sedang melapuk (Hanks 2000; Noerdjito 2010; Raje et al. 2012). Kumbang dewasa merupakan pemakan nektar, pucuk daun, dan kulit kayu (Noerdjito 2011). Beberapa jenis kumbang ini hidup pada kayu tanaman industri, sehingga dianggap sebagai hama (Noerdjito 2012). Beberapa spesies kumbang ini juga mempunyai tumbuhan inang spesifik, namun beberapa spesies dapat hidup pada berbagai tumbuhan (Waqa-Sakiti et al. 2013). Kumbang antena panjang menggunakan reseptor penciuman untuk menemukan tanaman inang yang cocok (Linsley 2002; Goldsmith et al. 2007).

Selain hama ditemukan pula predator dan parasitoid. Namun jika dilihat dari komposisi antara hama dan musuh alami tersebut, jumlahnya sangat tidak seimbang (Gambar 2). hal ini memungkinkan terjadi karena dalam budidaya tanaman melon yang dilakukan pada penelitian ini, dilakukan aplikasi pestisida dan fungisida. Kartohardjono (2011) menyatakan aplikasi pestisida dapat berdampak negatif langsung bagi musuh alami, dimana musuh alami terbunuh sehingga laju pertumbuhan populasi hama meningkat. Sebagai contoh, aplikasi pestisida isoprocarb (Miprin 50 WP) menurunkan kepadatan populasi predator pada tanaman tebu, tetapi tidak berpengaruh nyata pada hama kutu perisai Aulacaspis tegalensis (Hasibuan 2004).

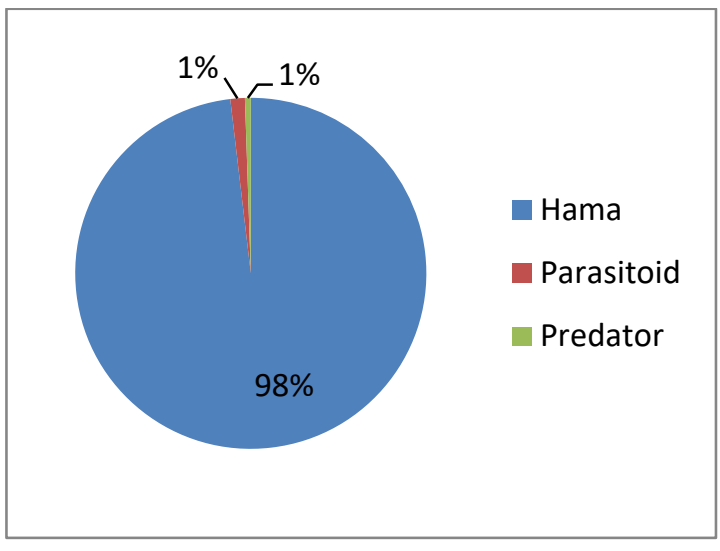

Gambar 2. Persentase komposisi hama dan musuh alami

Predator yang ditemukan adalah spesies Sphecidae sp. sebanyak 2 individu. Sphecidae merupakan serangga predator yang menyerang nimfa Grylotalpa sp., kutu Aphids, kepik dan ordo Lepidoptera. Larva disengat atau dilumpuhkan kemudian dibawa ke sarangnya sebagai makanan generasinya (Gullan dan Cranston 2005). Berdasarkan data pengamatan, hama yang kemungkinan dapat diserang oleh predator spesies Sphecidae yang ditemukan yaitu kepik dan kutu Aphids.

Spesies parasitoid yang ditemukan adalah spesies Braconidae sejumlah 3 individu, Acanthinevania sp. sebanyak 1 individu dan 1 individu Ichneumonidae. Braconidae dan Ichneumonidae merupakan kelompok parasitoid yang dapat bersifat endoparasitoid atau ektoparasitoid, dan memiliki peran penting dalam pengendalian hayati (Rustam 2004). Mekanisme parasitisme keduanya yaitu dengan hinggap pada larva sasarannya dan kemudian meletakan telur ke dalam tubuh larva tersebut, kemudian telur tersebut menetas menjadi larva dan akan memakan tubuh inangnya sehingga menyebabkan kematian serangga inang. Dalam tubuh satu larva bisa terdapat 50-150 telur/larva Braconidae atau Ichneumonidae. Jenisjenis hama inang Braconidae dan 
Ichneumonidae diantaranya yaitu ulat, kutu daun, kepik dan wereng. Menurut Deans dan Huben (2003), Acanthinevania merupakan salah satu parasitoid yang menyerang ulat atau larva serangga lain yang sering kali merupakan hama bagi banyak tanaman pertanian atau perkebunan.

Berdasarkan analisis indeks keanekaragaman Shannon-Wiener, nilai H' untuk keanekaragaman serangga pada tanamam melon adalah 0.820 , maknanya adalah nilai keanekaragaman serangga pada tanaman melon tergolong sangat rendah. Rendahnya nilai $H^{\prime}$ dapat disebabkan karena sedikitnya jumlah individu yang ditemukan dari masingmasing spesies serangga. selain itu, adanya dominansi suatu spesies juga dapat mempengaruhi nilai indeks tersebut. dari hasil pengamatan, dominansi spesies tertinggi ditemukan pada spesies lalat buah (Batrocera spp.).

Hal tersebut sesuai dengan Rizali et al. (2002), keanekaragaman spesies terdiri dari dua komponen, yaitu jumlah spesies dalam komunitas (disebut kekayaan spesies) dan kesamaan spesies yang menunjukkan klimpahan spesies tersebut (jumlah individu, biomassa, penutup tanah) tersebar antara banyak spesies tersebut.

\section{KESIMPULAN}

1. Hama dominan yang menyerang tanaman melon pada fase generatif yaitu lalat buah.

2. Ditemukan juga tiga spesies parasitoid dan satu spesies predator. Parasitoid yang ditemukan yaitu Braconidae, Achantinevania sp. dan Hymenoptera sedangkan predator yang ditemukan adalah Sphecidae.

\section{DAFTAR PUSTAKA}

Antari DMN, Sumiarti KI, Darmiati NN, dan Sudiarta PI. 2014. Uji galur dan varietas tanaman melon terhadap serangan hama lalat buah (Bactrocera dorsalis Complex) di Dusun Sandan, Desa Bangli, Kecamatan Baturiti. Kabupaten Tabanan. Jurnal Agroekoteknologi Tropika 3(2):1-5

Awaludin E, Suwarno WB, Sobir. 2010. Uji pendahuluan melon (Cucumis melo L.) hibrida potensial hasil pemuliaan Pusat Kajian Buah Tropika IPB. Makalah Seminar Departemen Agronomi dan Hortikultura. Bogor (ID): IPB

Badan Pusat Statistik (BPS). 2016. Statistik Tanaman Sayuran dan Buah-Buahan Semusim tahun 2016. Jakarta (ID): Badan Pusat Statistik Indonesia

Daryono B, Maryanto SD, Huda IN. 2011. Kebangkitan Pertanian Indonesia. Yogyakarta (ID): Kebun Pendidikan Penelitian Pengembangan Pertanian (KP4) UGM

Deans AR, Huben M. 2003. Annotated key to the ensign wasp (Hymenoptera: Evaniidae) genera of the world, with descriptions of three new genera. Proceedings of the Entomological Society of Washington 105: 589-875

Dirjen Hortikultura. 2015. Statistik produksi Hortikultura Tahun 2014. Jakarta (ID): Dirjen Hrtikultura

Goldsmith S, Gillespie H, Weatherby C. 2007. Restoration of Hawaiian montane wet forest: endemic longhorned beetles (Cerambycidae: Plagithmysus) in koa (Fabaceae: Acacia koa) plantations and in intact forest. The Southwestern Nat. 52(3):356-363

Gullan, Cranston. 2005. Phylogeny of the insect orders. [internet]. [diunduh 2018 Januari 28]. Tersedia pada: https://courses.cit.cornell.edu/ent20 1/content/predators

Hanks LM. 2000. Influence of the larval host plant on reproductive 
strategies of Cerambycid beetles. Annu Rev Entomol. 44(1):483-505. doi: 10.1146/annurev.ento.44.1.483

Hasibuan R. 2004. Evaluasi lapang terhadap dampak apikasi insekisida isoprocarb pada serangga predator dan hama kutu perisai Aulacaspis tegalensis Qhnt. (Homoptera: Diaspididae) di pertanaman tebu. $J$. hama dan Penyakit tumbuhan Tropika. 4(2): 68-73

Huda IN. 2009. Perakitan dan pembandingan karakter fenotip buah melon (Cucumis melo L.) kultivar gama melon basket dengan kultivar melon komersial [skripsi]. Yogyakarta (ID): Fakultas Biologi Universitas Gajah Mada

Kardinan A. 2003. Mengenal Lebih Dekat Selasih Tanaman Keramat Multi Manfaat. Jakarta (ID): Agromedia

Kartohardjono A. 2011. Penggunaan musuh alami sebagai pengendalian hama padi berbasis ekologi. Pengembangan Inovasi Pertanian. 4(1):29-46.

Linsley EG. 2002. Ecology of Cerambycidae. Annu Rev Entomol. 4(1):99-139. doi: 10.1146/annurev.en.04.010159.000 531

Noerdjito WA. 2010. Arti Kebun Raya Bogor bagi kehidupan kumbang antena panjang (Coleoptera, Cerambicidae). $J$ Biol Indon. 6(2):289-292

Noerdjito WA. 2011. Evaluasi kondisi hutan berdasarkan keragaman kumbang antena panjang (Coleoptera: Cerambycidae) di kawasan Gunung Slamet. Berita Biologi. 10(4):521-531

Noerdjito WA. 2012. Dampak kegiatan manusia terhadap keragaman dan pola distribusi kumbang antena panjang (Coleoptera: Cerambycidae) di Gunung Salak, Jawa Barat. J Biol Indon. 8(1):5769
Raje KR, Abdel-Moniem HEM, Farlee, Ferris VR, Holland JD. 2012. Abundance of pest and benign Cerambycidae both increase with decreasing forest productivity. Agri Forest Entomol. 14:165-169. doi: 10.1111/j.1461-9563.2011.00555

Rante CS. 2000. Pengendalian hama Plutella xylostella dengan parasitoid Diadegma eucerophaga pada pertanaman kubis di Kecamatan Tompaso, Kabupaten Minahasa. Eugenia. 6(4): 279-284

Kranz JH, Schmutterer, Koch. 1997. Diseases, Pest and Weeds in Tropical Crops. New York(USA): John Wiley and Sons

Rizali A, Buchori D, Triwidodo H. 2002. Keanekaragaman serangga pada lahan persawahan-tepian hutan indikator untuk kesehatan lingkungan. Jurnal Penelitian. 9(2)

Rukmana R. 2006. Budidaya Melon Hibrida. Yogyakarta (ID): Kanisius Rustam R. 2004. Potensi parasitoid Opius sp. (Hymenoptera; Braconidae) dalam menekan populasi hama penggorok daun Liriomyza sp. (Diptera; Agromyzidae). Makalah Pribadi Pengantar Falsafah Sains (PPs 702). Institut Pertanian Bogor. [internet]. [diunduh pada 2018 Januari 28]. Tersedia pada www.rudyct.com

Siregar AS, Bakti D, Zahara F. 2014. Keanekeragaman jenis serangga di berbgai tipe lahan sawah. Jurnal Online Agroekoteknologi. 2(4): 1640-1647

Van Sauers-Muller A. 2005. Host Plants of the Carmbola fruit fly, Bactrocera carambolae, in Suriname, South America. Neotrapical Entomology.

Waqa-Sakiti H, Stewart A, Cizek L, Hodge S. 2013. Patterns of tree species usage by long-horn beetles (Coleoptera:Cerambycidae) in Fiji. Pacific

Sci. 68(1):1-16. 